\title{
N6-methyl group of adenine further increases BI stability of DNA compared to C5-methyl
} groups (Supplementary information)

Fajar R. Wibowo, Michael Trieb, Christine Rauch, Bernd Wellenzohn and Klaus R. Liedl ${ }^{1}$ Institute of General, Inorganic and Theoretical Chemistry University of Innsbruck, Innrain 52a, A-6020 Innsbruck, Austria<smiles>[H][R14]([H])([H])N([TlH])c1nc([2H])nc2c1n[Y]n2C</smiles>

\begin{tabular}{ccr}
\hline Atom name & Atom type & \multicolumn{1}{c}{ Charge } \\
\hline $\mathrm{N} 9$ & $\mathrm{~N}^{*}$ & -0.0177 \\
$\mathrm{C} 4$ & $\mathrm{CB}$ & 0.3976 \\
$\mathrm{C} 5$ & $\mathrm{CB}$ & 0.1946 \\
$\mathrm{C} 6$ & $\mathrm{CA}$ & 0.3873 \\
$\mathrm{~N} 1$ & $\mathrm{~N} 1$ & -0.7793 \\
$\mathrm{C} 2$ & $\mathrm{CQ}$ & 0.6300 \\
$\mathrm{H} 2$ & $\mathrm{H} 5$ & 0.0478 \\
$\mathrm{~N} 6$ & $\mathrm{~N} 2$ & -0.3075 \\
$\mathrm{H} 61$ & $\mathrm{H}$ & 0.0359 \\
$\mathrm{CM}$ & $\mathrm{CT}$ & -0.2029 \\
$\mathrm{HM} 1=\mathrm{HM} 2=\mathrm{HM} 3$ & $\mathrm{HC}$ & 0.1002 \\
$\mathrm{~N} 7$ & $\mathrm{NB}$ & -0.5474 \\
$\mathrm{~N} 3$ & $\mathrm{NC}$ & -0.7484 \\
$\mathrm{C} 8$ & $\mathrm{CK}$ & 0.0554 \\
$\mathrm{H} 8$ & $\mathrm{H} 5$ & 0.2784 \\
\hline & & \\
\hline Atom name & Atom type & Charge \\
\hline $\mathrm{N} 1$ & $\mathrm{~N}$ & 0.0487 \\
$\mathrm{C} 2$ & $\mathrm{C}$ & 0.5657 \\
$\mathrm{O} 2$ & $\mathrm{O}$ & -0.5704 \\
$\mathrm{~N} 3$ & $\mathrm{NA}$ & -0.4400 \\
$\mathrm{H} 3$ & $\mathrm{H}$ & 0.3219 \\
$\mathrm{C} 4$ & $\mathrm{C}$ & 0.6523 \\
O4 & $\mathrm{O}$ & -0.5686 \\
$\mathrm{C} 5$ & $\mathrm{CM}$ & -0.3483 \\
$\mathrm{H} 5$ & $\mathrm{H} 4$ & 0.1704 \\
$\mathrm{C} 6$ & $\mathrm{CM}$ & -0.1718 \\
$\mathrm{H} 6$ & $\mathrm{H} 4$ & 0.2133 \\
\hline & & \\
& &
\end{tabular}

Figure 1. Atomic type and charge distribution for N6-methyladenine (top) and uracil (bottom)

\footnotetext{
${ }^{1}$ Corresponding author, email: Klaus.Liedl@uibk.ac.at
} 

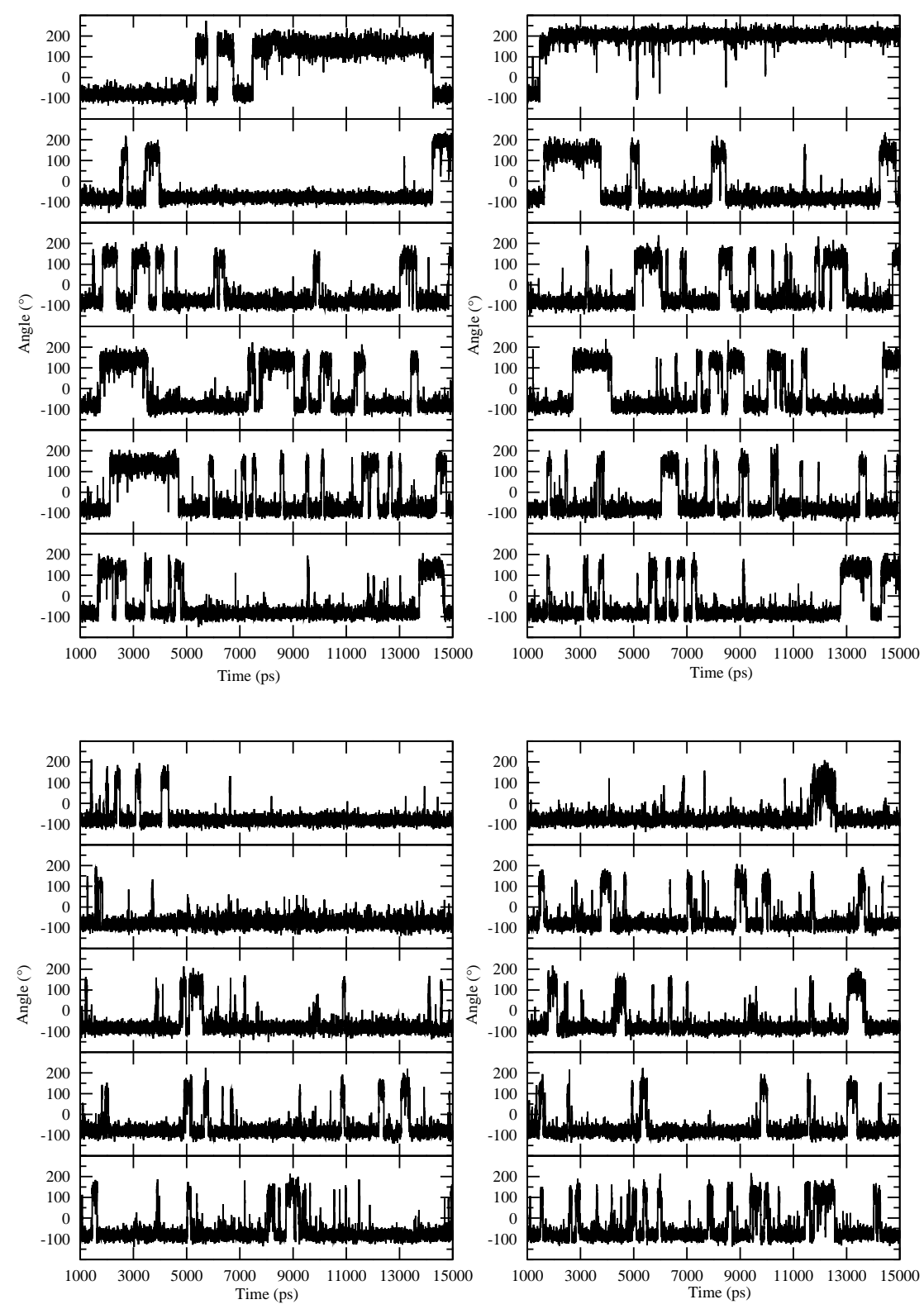

Figure 2. The time evolution of $(\varepsilon-\zeta)$ for GC (top) and CG (bottom). Left columns - strand 1 ; right columns - strand 2. 